Miguel Lamas Pardo

Luis Carral

Laura Castro-Santos

Juan Carlos Carral Couce

http://dx.doi.org/10.21278/brod68308

ISSN 0007-215X

eISSN 1845-5859

\title{
A REVIEW OF THE DRIVE OPTIONS FOR OFFSHORE ANCHOR HANDLING WINCHES
}

UDC 629.5.028.71

Review paper

\begin{abstract}
Summary
This article discusses the state of the art for driving technologies of anchor handling winches for offshore operations. These systems are necessary for anchor handling operations associated with installation of many types of moored floating offshore structures. To perform these operations, it is necessary to use specialized vessels known as AHT (Anchor Handling Tug) or AHTS (Anchor Handling Tug Supply) vessel, which incorporate specific equipment such as towing winches, but with higher performance than conventional tugs both in size and in technical performance. There are nowadays two main options for driving the Anchor Handling/Towing winches: hydraulic with low or high pressure motors, and electrical with AC motors driven by Variable Frequency Drives. Additionally, a new technology is appearing in the industrial sector which is starting to be applied in the marine sector, and in some cases for anchor handing winches: the permanent magnet motor. The aim of this paper is to discuss these driving technologies and their importance in the future of this part of the marine sector.
\end{abstract}

Key words: $\quad$ Offshore; Anchor Handling and Towing Winches; Permanent magnet motor;

\section{Introduction}

\subsection{The AHTS vessel and the AHT Winch}

The offshore oil rigs used in the Oil \& Gas sector are of very different types and have different ways of stationkeeping, depending on the waterdepth and environmental conditions in their intended location. Many of these platforms are positioned using heavy chain or wire cables attached to anchors fixed at the seabed.

In addition, the offshore renewable energy sector is increasing its development in the last years [1]. Although there are several types of marine renewable energies: tidal, currents, wave, wind, salinity, etc., the most important one is offshore wind, in which Europe is the leading player [2]. There are two main types of offshore wind energy platform: fixed systems and floating 
devices. The main difference between them is the fact that fixed technology has initially been used for shallow waters (up to 50-60 m) where most activity has occurred to date, and floating platforms are now being designed for deeper waters (more than $50-60 \mathrm{~m}$ of depth) [3] further offshore where higher wind speeds may be present. Therefore, the position keeping of the floating offshore wind devices will be developed in the future using different types of mooring and anchor systems.

For these offshore mooring works, the type of vessel used is the "Anchor Handling Tug Supply (AHTS) Vessel". As the name suggests, the main missions of these vessels are [4]-[7]:

- $\quad$ Tow the platform into position ("Tug") [8]

- Manage the deployment of the platform mooring lines and anchors to position the platform in its location (Fig. 1) ("Anchor Handling") [9].

- Perform operational support tasks such as platform supply ("Supply") [10].

- Perform other operations, such as serving as Vessel Rescue and Recovery Emergency ("Emergency Rescue and Recovery Vessel, ERRV") [4].

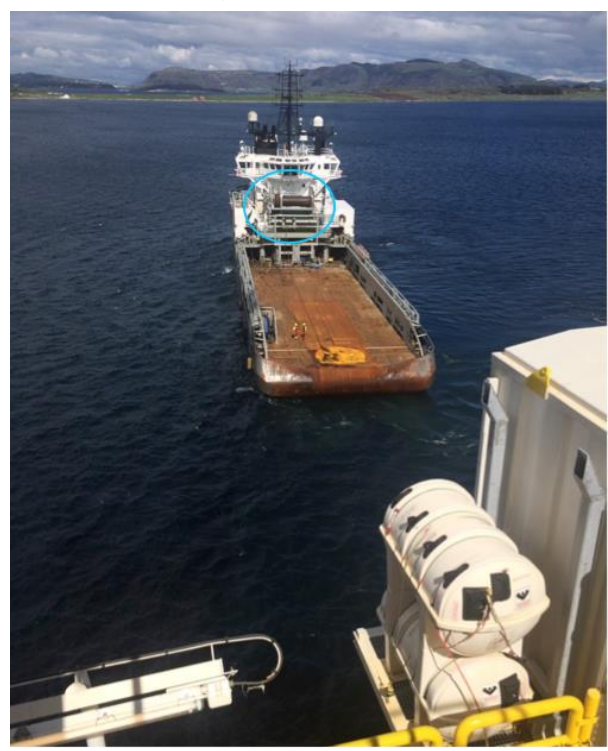

Fig. 1. AHTS vessel during the manoeuvre to position on the seabed anchor offshore platform type semi-submersible showing an Anchor Handling Winch (AHW) and a Towing Winch (TW).

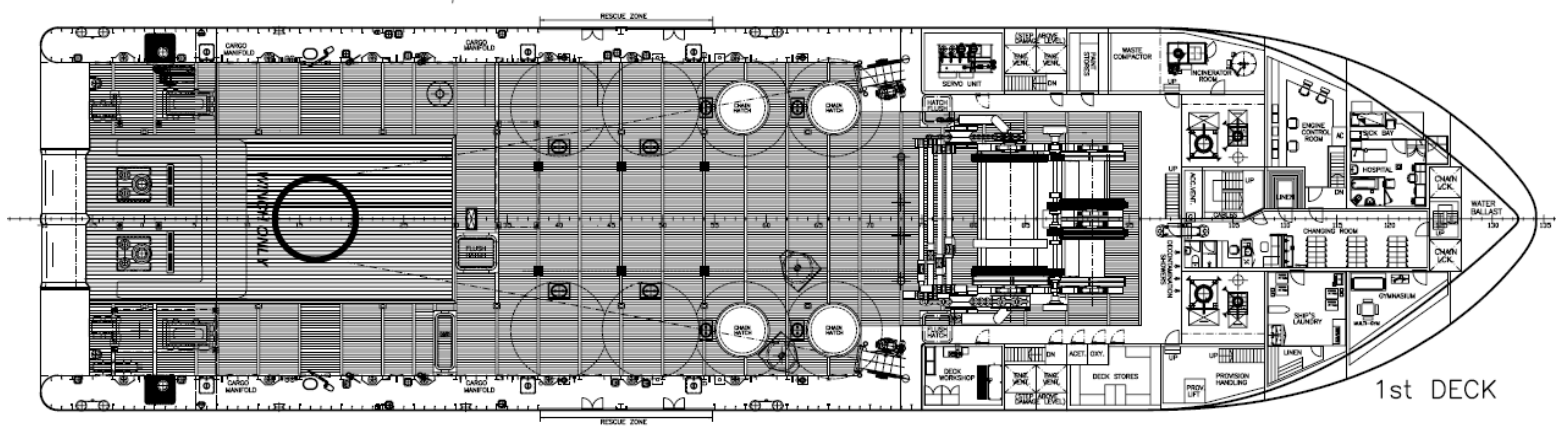




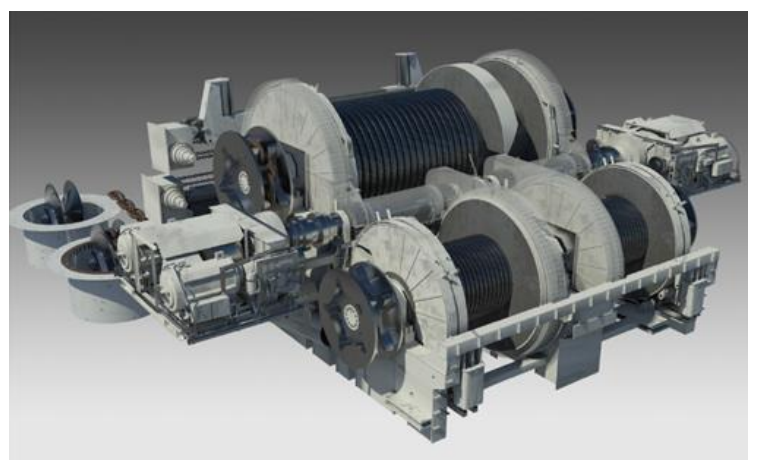

Fig. 2. Deck Layout of and AHTS Vessel class VS-491 with the Winch located in forward part of the deck [11], and AHTS Winch of the previous vessel type VS-491 [12].
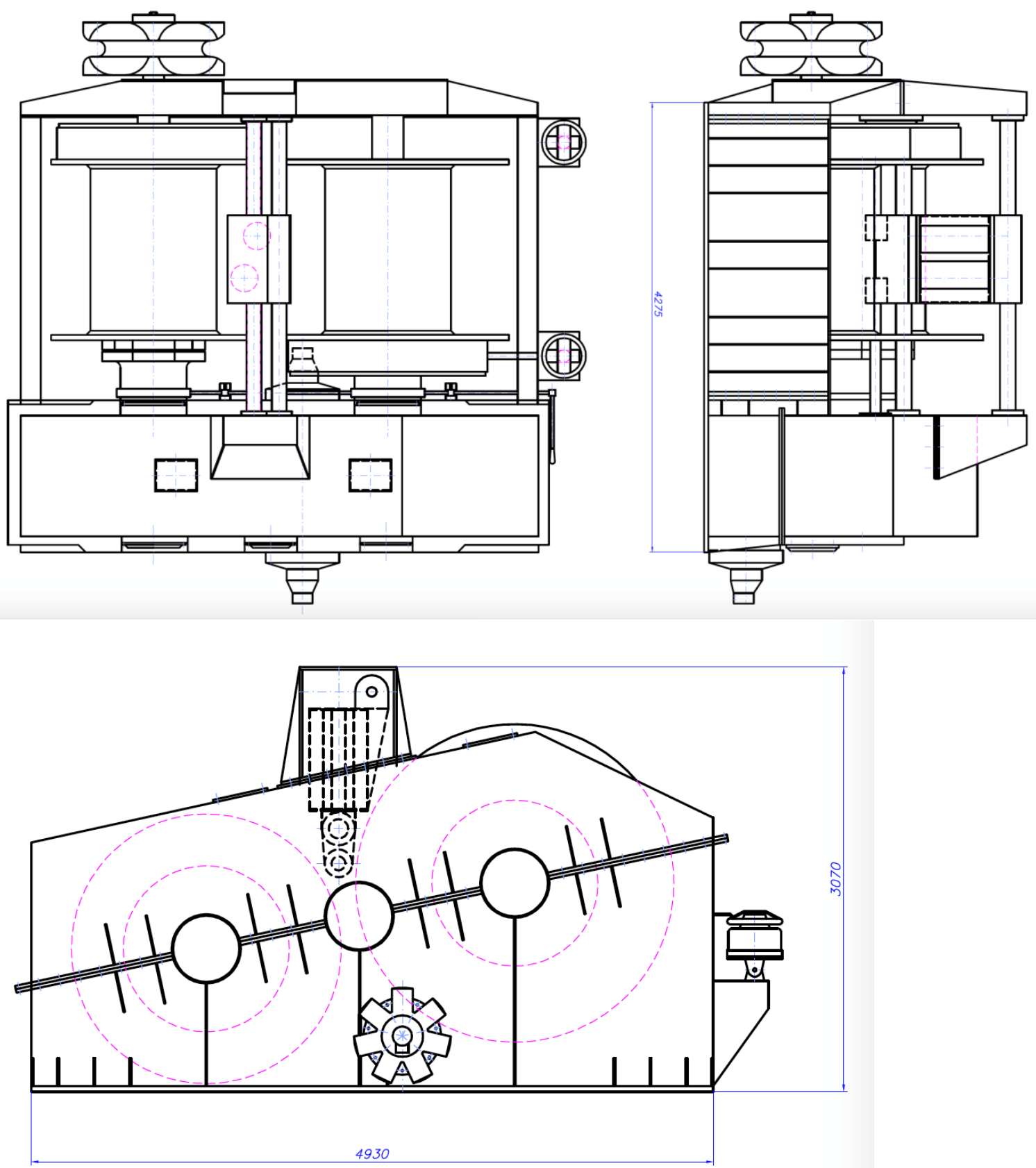

Fig. 3. Arrangement of components of a towing winch and anchor handling with stevedore system, equipped with traction in the first layer $150 \mathrm{~T}$ and $60 \mathrm{~mm}$ cable stowage capacity of $1330 \mathrm{~m}$ and $820 \mathrm{~m}$, powered by high-pressure hydraulics. Source: Carral design engineering solutions 
These types of AHTS vessels are fitted with specialised equipment for the work of towing and anchor handling. Although composed of various elements, the heart of this system is the winch for towing and anchor handling [6]. The winch is designed to handle wire rope and usually contains both Anchor Handling Drums (AHW) and Towing Drums (TW) (Fig. 2 and Fig. 3), as well as wire storage drums. The drums are normally connected to the same drive system. The anchor handling winch should have multiple gears to allow high pulling force at low gear, and higher speed at high gear. An arrangement with variable braking power should be present for cases when the tension is excessive [13]. The winch drive system may either be hydraulic, electric or diesel direct drive. The direction of rotation is normally underwind, so that the work wire has a small downward angle towards the stern of the vessel.

\subsection{Maximum traction winch as a design variable}

The main variable that defines these winches is the initial pulling capacity, normally expressed in tonnes at the first layer of wire. This defines the required power of the drive system [14]. Table 1 shows some examples of AHTS winch pulling power for typical AHTS, defined by their length and class/design. Here, the AHTS vessels have been divided into different categories (Low, Medium, High) according to the installed winch capacity. Three categories have been established: 200, 300 and $500 \mathrm{~T}-\mathrm{f}$, relating the value of the equipment capacity to an approximate indication of the length of the ship.

Table 1. Classification of AHTS vessels

\begin{tabular}{|l|l|l|l|}
\hline Vessel capacity & \multicolumn{1}{|c|}{ Low } & \multicolumn{1}{c|}{ Medium } & \multicolumn{1}{c|}{ High } \\
\hline Winch pull, First layer (tons) & 200 & 300 & 500 \\
\hline Length of vessel (m) & 55 & 73 & 92 \\
\hline Example & Class RAmpage 5500 & Class VS-473 & Class VS-491 \\
\hline
\end{tabular}

\subsection{AHW and TW winch control}

Within the advanced control of winches installed on ships [13], [15], [16], two possible solutions to maintain tension and speed within predetermined values coexist: constant tension (Tension Activated) mode and constant speed mode (Motion Activated). The first mode control system responds to changes in cable tension, paying out or pulling in wire as required to maintain tension. On the other hand, the constant speed mode allows speed to be continuously and automatically adjusted to provide a constant and speed of displacement of the end of the cable.

Regardless of that, the operation of all these types of ships requires winch speed variation by acting on the drive, regardless of whatever type of drive is used [9]. Therefore, the control function must as a minimum control its rotational speed, seeking to obtain the proper pull in or pay out speed.

\section{Main type of driving technologies for AHT winches}

Fig. 4. shows a simplified control and drive model for an winch anchor-handling [9], [13] 


\subsection{Control and drive of a winch}

Carral et al, (2016b) explains the three drive options of a winch commonly found on board:

- electric motor and a reducing gear (EL)

- hydrostatic transmission based on a hydraulic motor with low torque and high speed with a reducing gear (High Pressure Hydraulic - HPH) (Fig. 3).

- hydrostatic transmission based on a hydraulic motor of high torque and low speed with a direct drive to the winch (Low Pressure Hydraulic - LPH) (Fig. 2).

The control system function is to vary the speed of pull in and pay out using the action taken by the drive, regardless of whether this is electric or hydraulic type [9]. This solution requires the installation of a controller to vary the speed of the winch cable by acting on the angular speed of the motor.

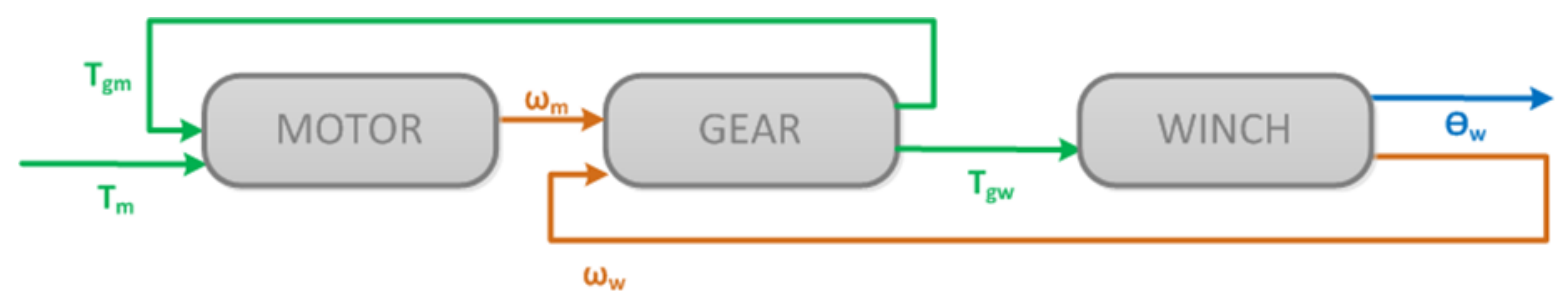

Fig. 4.Winch system is composed of the electric drive, the reducing gear and the set formed by the drum, the shaft and the spooling system.

The drive motor is a rotating axis driven by an input torque and delivering an output torque to the gearbox, where $\omega_{m}$ is the angular speed of the shaft, $T_{m}, T_{g m}$ are the torque delivered by the engine and the gearbox resistive torque. The mechanical gearbox, which is interposed between the electric drive and the winch shaft, has the function of adapting the engine output speed to the required speed of rotation of the winch [16]. This is achieved by the reduction ratio " $i$ ". Relations between angular speeds and torques have the following notation: input torque, angular speed and angular position in the input shaft (motor side) $\left(\omega_{m}, T_{g m}\right)$ and output reduction gear (winch side) $\left(\omega_{w} . T_{g w}\right)$

$$
\begin{aligned}
\omega_{w} & =i \cdot \omega_{m} \\
T_{g w} & =\frac{1}{i} T_{g m}
\end{aligned}
$$

Finally, the winch consists of a rotation shaft subjected to the action of the couples of the gearbox output and the traction of the cable on the corresponding layer of the winch drum.

\subsection{Winch drives for AHW and TW}

Nowadays, in the market two types of drives (motor+gear) can be considered for the AHTS vessels:

- Hydraulic, low pressure, the most widespread (LPH)

- Electric, three-phase asynchronous motor controlled by inverter (EL) 
The following objects are the main elements:

- AH-DRUM: drum for anchor handling operations

- TW-DRUM: drum for towing operations

- GEAR CASE: gearbox, mechanical interface

- ELECTRIC MOTOR: motor electric drive ( $n$ the case of hydraulic drive this is a hydraulic motor)

- GUIDE ROLLER: gypsy for anchor handling guide to the chain locker

- WATER BRAKE: water cooled brake used to slow the machine during fast wire run off (electric winches can use resistive braking)

As seen below, these types of drive have a number of advantages and disadvantages [14]. Today manufacturers focus on finding a new drive that has the advantages of both low-pressure hydraulic actuators and electrical induction motors, but at the same time avoids the drawbacks of each.

A drive which could meet these requirements is the permanent magnet motor (PMM). In these the following equation is fulfilled:

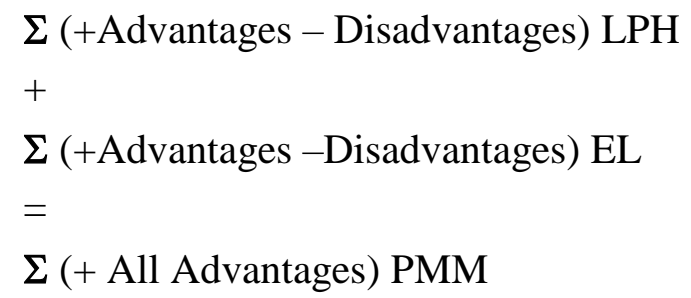

This is a technology which is still in its early stages, yet it has already been used in some anchor handling winches for other purposes.

\subsubsection{LPH}

The most widely used type of anchor handling systems is a hydraulic drive type, and in particular, the low hydraulic pressure system [17]. High pressure systems are used in some applications, but are less frequent. This design performs well on AHTS and on other vessels such as tugs and fishing boats [14], [18], mainly due to widespread experience with this type of drive by the owners and operators, and also by the great inertia of the sector to change from established solutions. De Angelis, V., (2009) performed a similar analysis between HPH and other drive types for the case of deepwater winches for use in biological oceanography and fisheries [19]. However, he did not take into consideration in the analysis the case of the LPH in the AHTS sector.

\section{Advantages}

The main advantage of the hydraulic system is that it allows precise and smooth control with high torque at low revolutions [17], [18]. 


\section{Disadvantages}

Although hydraulic drives have been the most used for years, they have a number of disadvantages that often allows the electric alternative to now be presented as the best option. These drawbacks are listed below:

Low efficiency. The low efficiency of hydraulic drives (which usually begin with an electric motor driven power pack) is well known and even acknowledged by Nürnberg A., (2010), who promotes the development of LPH instead of the EL asynchronous type [17].

Table 2 shows the performance of each of the alternatives, showing that asynchronous electric has a much higher mechanical performance:

Table 2. Efficiency in hydraulic and electric drives [17].

\begin{tabular}{|l|c|c|}
\hline Type of drive & Total Efficiency $(\eta)$ & $\begin{array}{c}\text { Installed Power PINST } \\
\text { 4500KN@9M/MIN }\end{array}$ \\
\hline LPH & $54 \%$ & $1250 \mathrm{~kW}$ \\
\hline HPH & $65 \%$ & $1040 \mathrm{~kW}$ \\
\hline Electric asynchronous & $70 \%$ & $965 \mathrm{~kW}$ \\
\hline
\end{tabular}

Higher noise and vibration. The hydraulic power packs and piping are noisy and this can be a problem if installed close to living spaces on the vessel. This is an increasing problem as standards for crew accommodation are constantly improving in all sectors.

Higher pollution risk. By having the possibility for oil leaks.

Large and heavy equipment. In hydraulic systems large tanks, pumps and pipes are used, because of the huge flow needed to get the power and speedrequirements of these machines. Thus:

- A lot of space is needed under cover to accommodate the power unit.

- The required pipe diameters of the order of $150 \mathrm{DN}$ and expensive and difficult to fabricate and install

- Weight and space are costly parameters to provide on any floating vessel

Need for high maintenance. This is because these are delicate machines, subject to contamination of the hydraulic oil.

\subsubsection{Electric motors using three-phase asynchronous motors}

Apart from the drawbacks described above, a number of developments in recent years have led manufacturers of anchor handling systems towards adoption of electric drives. Such circumstances are primarily:

- Increased diesel electric propulsion systems on the vessels, which means that there are already a large number of electrically powered systems on board [20]. 
- The drive (torque and speed control) of asynchronous motors is much improved in recent years thanks to the technology of variable frequency [17].

These and other circumstances have led winch manufacturers to try to replace hydraulic drives with the less polluting and more efficient three-phase asynchronous electric motors (Fig. 4).

Advantages. Electrically operated winches transfer electrical energy directly into mechanical energy and so have a better efficiency compared to hydraulic systems [19].

Disadvantages. However, the electric system also has a number of drawbacks:

- Three-phase asynchronous motors need a lot of power, and consequently the necessary equipment can be expensive

- Due to the high motor speed, the requirement of expensive planetary / epicycloid reduction gears is necessary, introducing very complicated mechanisms

- The response in terms of speed and torque control is less accurate than the hydraulic drives, although it is improving rapidly with frequency inverters

2.3 Advantages of an electric drive versus the traditional LPH drive

The most relevant aspects in terms of comparing these two drives are:

- Efficiency

- Weight and volume

- Maintenance

- Useful life

- Safety

- Noise

- Pollution

Regarding efficiency, the electric drive is more efficient (Fig. 4). As a result, less power can obtain the same benefits as with a hydraulic system. All of this improves the energy balance of the ship, estimated to obtain savings of between $30 \%$ to $40 \%$ compared with the LPH alternative [17]. Similarly, the capacity of regeneration during braking should be taken into account, also obtaining occasional energy savings [19], [21]. It is important to notice the existence of an important electricity generation capacity in the ship to be used in the auxiliary systems and, even, the propulsion systems. In the LPH-option this electrical energy should be converted into pressure energy using a Hydraulic Pressure Unit (HPU). 


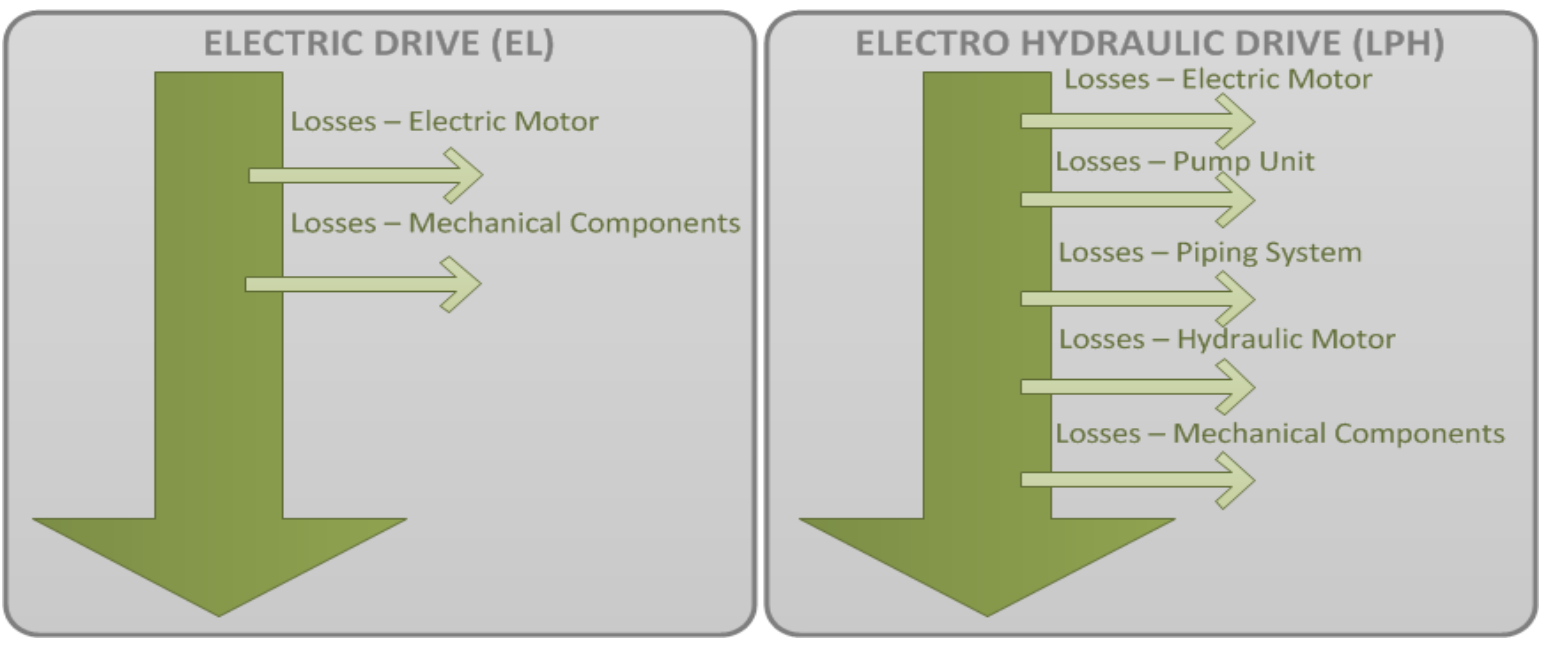

Fig. 4.SANKEY diagram of a LPH and a EL drive.

Regarding weight and volume, these are important factors due to the high installed power of the drives of these systems. At the same time, this will lead to higher values in the weight of the associated equipment and services finally affecting the lightship weight and displacement of the ship and thus its building and operating costs [22]. The EL drive has less volume and weight demand. However, it must be noted that the variable frequency drives cabinets contain temperature sensitive components and usually require to be located in air conditioned spaces in the vessel.

Considering maintenance, EL systems reduce the maintenance labour during the life of the equipment [19]. This is due to two reasons: through the use of more standard elements, which makes providing them easier; and due to the presence of fewer moving parts or parts subject to deterioration due to dirt. It is also important to note that LPH depends on a small number of system manufacturers, which may tend to keep prices high. On the other hand, it must be noted that hydraulic systems generally require a lower technology capability onboard, while specialist crew members or vendor support is required because of the PLC logic and specialist electrical components used in the variable frequency drives.

Regarding safety, the presence of hydraulic oil, with the inevitable losses that occur at connections and couplings, leads to necessary cleaning tasks on the decks. Despite the application of this preventative action, with the EL system a safer working platform should be obtained. This factor is very important because it affects the risk of accidents to the staff involved in the complicated operations of anchor handling.

In terms of noise, the hydraulic equipment is noisier than the electric system because of its pumps, which are characterized by their high level of noise.

Finally, in terms of pollution, the EL is more respectful of the environment for two reasons: firstly eliminating potentially polluting components, such as oil, and avoiding the installation of large diameter pipes, drains, etc. Therefore, it is equipment which is more consistent with the "Green Passport" that these ships should hold to operate with oil platforms in safe and environmentally friendly conditions, eliminating potential tank cleaning or oil leaks at sea. Secondly, consuming less fuel for the electricity generation achieves a reduction of pollutant emissions (Fig. 5) 


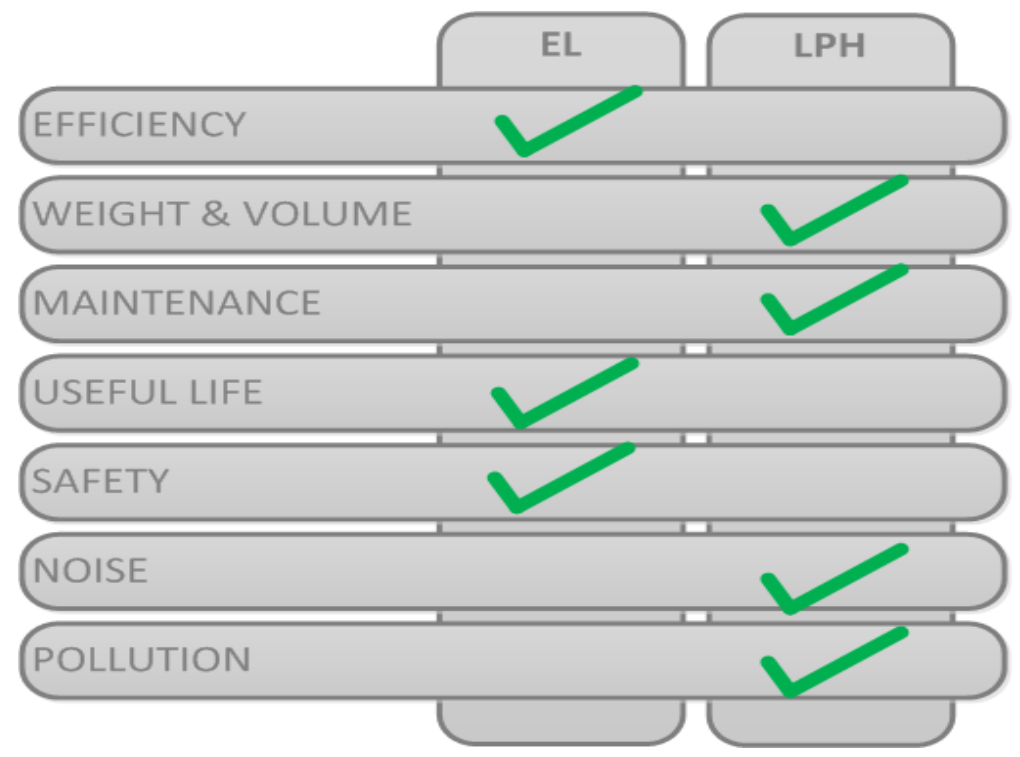

Fig. 5. Comparative between LPH and EL drives.

\section{Electric drives with PMM.}

\subsection{Evolution of classic engines}

The evolution of developing electric motors is based on three generations or stages:

- $\quad 1^{\text {st }}$ Generation

- $2^{\text {nd }}$ Generation

- $3^{\text {rd }}$ Generation

$\mathbf{1}^{\text {st }}$ Generation are the "classic" engines. The first generation has three engine types which can be regarded as classic: the DC (Direct Current) motor with collector and excitation winding, the induction AC (Alternating Current) motor (asynchronous) and the AC synchronous motor. If these are coupled to suitable electronic devices it is possible to achieve a variable speed. It is in combination with these engines that most of the technological and commercial development of power and control electronics that exist today has been obtained [23].

$2^{\text {nd }}$ Generation are the PMM. The engines of the second generation are derived from the first generation by replacing excitation windings with permanent magnets. The synchronous motor, to perform the above replacement, automatically becomes a brushless motor. However, in the DC motor the inductors stator poles can simply be replaced by permanent magnets.

$3^{\text {rd }}$ Generation allows an additional transformation. In this sense, reversing the roles of the rotor and stator it can go from the DC PMM to the DC permanent magnets brushless. In this third generation, the switched reluctance motor is also included, which is not derived from any of the above.

The engine considered here is the $2^{\text {nd }}$ Generation permanent magnet synchronous motor for its applicability to drive high-performance machines. 
The PMM are used in industry in applications which require variable speed and constant torque with high efficiency, such as compressors, conveyor belts, etc. Moreover, its use is increasing in projects that include soft torque, low noise and low vibration levels, such as for example, elevators [23].

In addition, they have been used for decades at a small scale for their good weight-performance ratio, for example in the computer industry. In recent years, they have been perfected offering high accuracy and reliability to applications requiring high torque and low speed (as in the case of anchor handling winches). This new technology of PMM helps to eliminate reductors in many industrial sectors such as the paper industry [24]. An example is shown in Fig. 6:

600 r.p.m. 1,500 r.p.m.

(a)

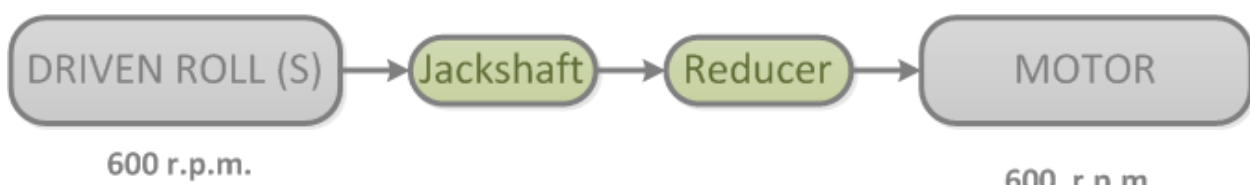

600 r.p.m.

(b)

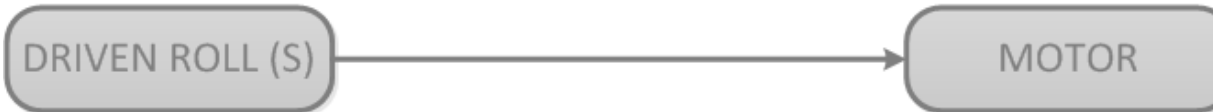

Fig. 6. Setting the drive with (a) conventional induction motor, gearbox and drive shaft; (b) Direct drive system with PMM [24]

Nowadays, PMM are extensively used in servomotors, electric drives for positioning, robotics, machine tools, elevators, etc. Machines of $1 \mathrm{MW}$ of power have been constructed for driving submarines [25]. They can also be applied in generating and pumping using solar or wind energy [26].

\subsection{Advantages of the drives for PMM against asynchronous (induction)}

The PMM are used in industry in applications which require variable speed with constant torque and high efficiency and projects in which low noise and low vibration are required. In comparison with an induction motor of the same power, the lifetime of the PMM is significantly higher, while its volume is reduced by approximately $47 \%$, resulting in a high ratio torque/volume, and the weight decreases about $36 \%$ [21] .

The main advantages [21], [27] are summarized in the following aspects;

- Small size

- High efficiency, with 15-20\% lower losses in the induction motor [27]

- High dynamic torque

- Wide range of speeds and precise regulation

- Longer life in bearings and isolation, due to their reduced working temperature

- High accuracy and reliability when high torque and low speed is needed

- High performance

- Less maintenance

- They are machines with very smooth start 
- They can reach high speeds

- They improve the power factor to a satisfactory extent

However, their disadvantages are:

- Their powers are not very high

- Tendency to demagnetization

- You can not change the characteristics of the machine

- They are expensive

- Incipient technology

However, their use in the marine field has so far been only in a few known cases linked to the main propulsion [28], and only recently has it begun to be applied to winches for anchor handling and other offshore applications [29].

\section{PMM in marine applications}

\subsection{PMM in marine applications for main propulsion}

Although its advantages seem suitable for use as main propulsion motors (high torque and low speed are required), the use of PMM is still emerging in this field because the technology is not yet too advanced [28]. The main advantage of using PMM in main propulsion is that it is possible to eliminate the reduction gear. Some examples exist in the Offshore and Military sectors[28], [30].

\subsection{PMM in anchor handling winches.}

These engines have a low moment of inertia and low mechanical time constant, which makes them very competitive with hydraulic systems to operate winches. However, its use in winches of AHTS vessels has not been implemented so far more than in a few cases, mainly because the power required in these types of machines makes the final product more expensive. The Norwegian engineering firm XOT, points out the following advantages of PMM, which make them ideal for applications in winches:

- Good for dynamic applications of winches due to:

- High torque for volume

- Requires less reduction ratio in the gearbox

- The lower inertia requires less maximum power

- Shorter dimensions

- Higher efficiency compared to induction motors

- It is possible to obtain a high output torque at low revolutions

- Good heat dissipation and, therefore, good capacity to be overcharged

However, there are only a few applications of PMM for driving winches in anchor handling, although manufacturers exist who are trying to develop this application. An example is (Fig. 7) 
National Oilwell Varco's AHT winch which is powered by standardized and high efficient drive units each driven by 4-8 PMM. Each unit has the LOADLIM safety release and high-speed payout system, integrated into the gearbox. The NOV AHT winch system combines the best technology available for rotating machinery providing excellent tension control for the operator and a highly redundant drive system [12].

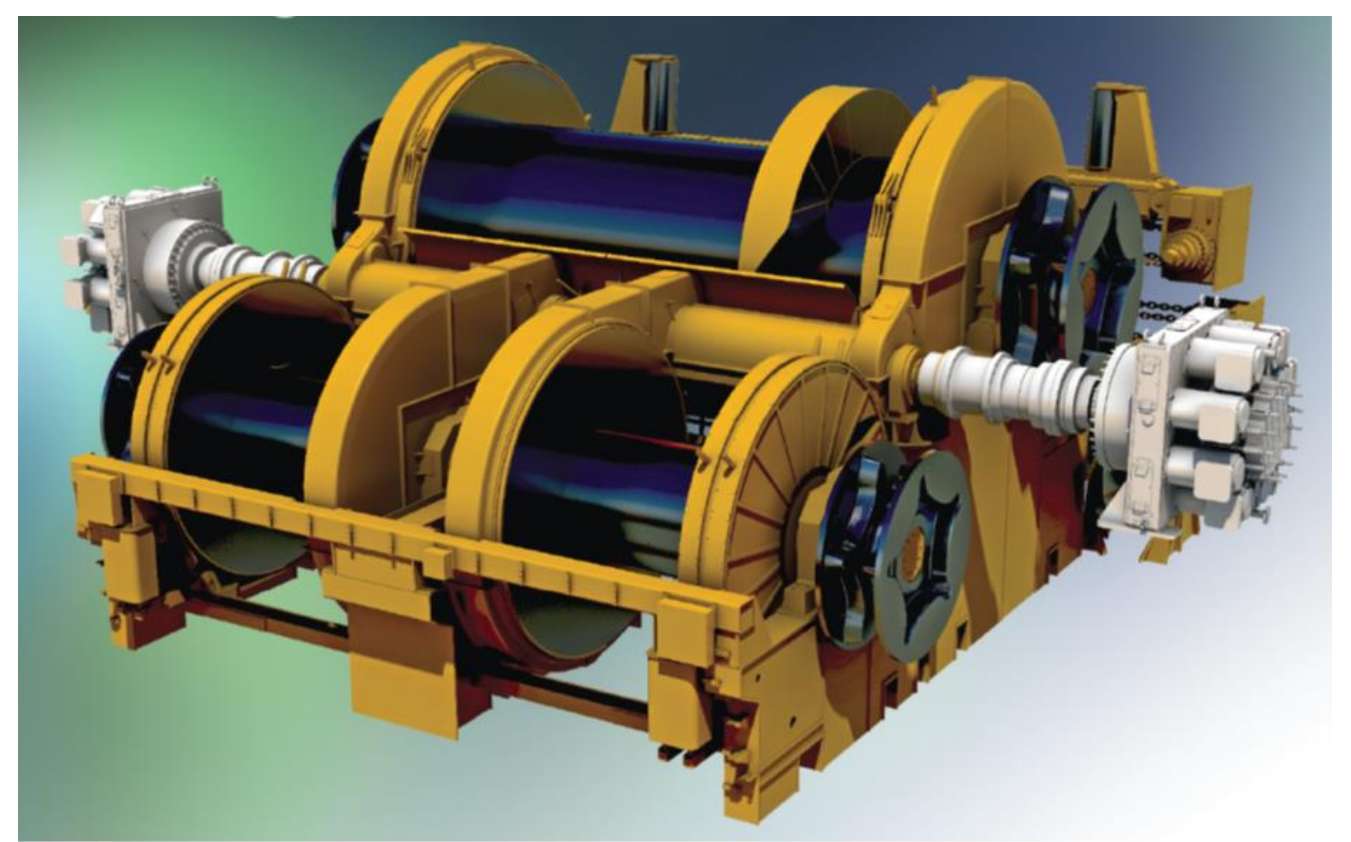

Fig. 7.Offshore Anchor Handling Winch powered by eight PMM. National Oilwell Varco

\section{Comparisons}

At present, electric (EL) and hydraulic (LPH) drives coexist in motorizing AHW and TW, with their different advantages and efficiencies, as Table 4 reflects.

Table 1. Types of drives for towing winches and anchor handling winches. Source: Authors own

\begin{tabular}{|l|l|l|l|}
\hline Type of drive & \multicolumn{1}{|c|}{ HYDRAULIC } & $\begin{array}{l}\text { ASYNCHRONOUS } \\
\text { ELECTRIC }\end{array}$ \\
\hline Type of motor & LPH & $\begin{array}{l}\text { Asynchronous three-phase } \\
\text { motor }\end{array}$ & Permanet magnet motors \\
\hline $\begin{array}{l}\text { Mechanical } \\
\text { interface }\end{array}$ & Planetary gearbox & Planetary gearbox & $\begin{array}{l}\text { Gearbox with only 2/3 stepsor } \\
\text { directly coupled }\end{array}$ \\
\hline Speed and control & $\begin{array}{l}\text { High } \\
\text { Flow control in the hydraulic } \\
\text { power unit }\end{array}$ & $\begin{array}{l}\text { Medium } \\
\text { Variable frequency drive }\end{array}$ & $\begin{array}{l}\text { High } \\
\text { Variable frequency drive }\end{array}$ \\
\hline Efficiency & $54 \%$ & $70 \%$ & $90 \%$ (expected) \\
\hline Occupied space & Low & Medium & High \\
\hline Noise & \multicolumn{2}{|l}{} \\
\hline Pollution & Oil spill risk & No & No \\
\hline Maintenance & High & Low & Low \\
\hline
\end{tabular}

The use of electric drives in AHW and TW winches is increasing compared with hydraulic drives, due to the advantages evidenced in Table 5: 
Table 2.Electrical versus hydraulic solutions

\begin{tabular}{|l|l|}
\hline ADVANTAGE & DISADVANTAGE \\
\hline$\bullet \quad$ Improved health, safety, environment, operation & $\bullet \quad$ Higher Inertia \\
$\bullet \quad$ Easier installation and maintenance & $\bullet \quad$ More space consuming \\
\hline
\end{tabular}

\section{Conclusions}

At present, electric (EL) and Low Pressure Hydraulic (LPH) drives coexist in motorizing Anchor Handling Winch (AHW) and Towing Winch (TW), with their different advantages and efficiencies. In this sense, LPH have a medium efficiency, a high flow control in the hydraulic power unit, but high maintenance demand. However, electric drive with PMM offers a high efficiency, high speed control by variable frequency drive and low maintenance.

Manufacturers of winches for towing and anchor handling have been forced to increase the installed power due to the requirement to equip AHTS vessels of higher capacity and bollard pull, suitable for anchoring platforms that have to operate in areas of very high water depth (up to $3000 \mathrm{~m}$ ). This fact may also affect the offshore wind energy industry, whose installing depth is growing higher and higher (though still much shallower than the offshore industry).

The demand of AHW and TW with higher traction and storage capacity for mooring lines means that the necessary equipment power grows and, thus, an increasing need for efficiency in their drives.

In these vessels, the already established advances in the use of hybrid diesel-electric power plant, linked to other aspects such as dynamic positioning, makes the use of electric drives in AHW and TW winches increase compared with hydraulic drives, due to the improvements of health, safety, environment and operation and their easier installation and maintenance.

The development of the second generation of electric drives leads to the PMM drive which has advantages over induction motors such as improved health, safety, environment, easier operation, easier installation and maintenance, combined with reduced inertia and reduced size.

\section{REFERENCES}

[1] European Wind Energy Association (EWEA), 'Deep water. The next step for offshore wind energy', 2013.

[2] A. R. Henderson, C. Morgan, B. Smith, H. C. S??rensen, R. J. Barthelmie, B. Boesmans, H. C. Sorensen, R. J. Barthelmie, and B. Boesmans, 'Offshore Wind Energy in Europe? A Review of the State-of-the-Art', Wind Energy, vol. 6, no. 1, pp. 35-52, Jan. 2003. https://doi.org/10.1002/we.82.

[3] A. R. Henderson, M. B. Zaaijer, B. Bulder, J. Pierik, R. Huijsmans, M. Van Hees, E. Snijders, G. H. Wijnants, and M. J. Wolf, 'Floating windfarms for shallow offshore sites', in Proceedings of the 14th International Offshore and Polar Engineering Conference, 2004, vol. 1, pp. 120-127.

[4] J. Gaston, The tug boat. Sparkford: Hayne Publising, 2009.

[5] J. Ter Haar, Towing Manual. Rotterdam: STC - Group, 2010.

[6] L. Carral Couce, J. Fraguela Formoso, R. Villa Caro, T. Calatayud, and C. Carral Couce, J. C. Lamas Pardo, M. Alvarez Feal, 'Estudio del valor total de la tracción en la maquinaria de cubierta de un Buque Offshore Anchor Handling Tug', in Actas del Congreso Internacional Copinaval, Panamá, Instituto Panamericano de Ingeniería Naval, 2014.

[7] L. Carral-Couce, S. Naya, C. Alvarez Feal, S. Lamas Pardo, and J. Tarrio Saavedra, 'Estimating the traction factor and designing the deck gear for the anchor handling tug', Proc. Inst. Mech. Eng. Part MJournal Eng. Marit. Environ., 2017. 
[8] M. Hancox, Towing -The Oilfield Seamanship Series - Volume 4. London, UK: , Oilfield Publications Limited, 1998.

[9] L. Wennersberg, 'Modeling and Simulation of Anchor Handling Vessels', Norwegian University of Science and Technology - Department of Engineering Cybernetics, 2009. [Online]. Available: www. divaportal.org/smash/get/.../FULLTEXT01.pdf. [Accessed: 24-Nov-2015].

[10] M. Fun-sang, R. da Silva, and J. Caprace, 'Prediction of delays in supply logistics of offshore platforms', in Actas del XXIV Congreso Internacional Copinaval, Montevideo, Instituto Panamericano de Ingeniería Naval Copinaval., 2015, p. 763.

[11] Boa Vision, 'BOA VS 491', 2016. [Online]. Available: www.boa.no/Files/Billeder/vessels/AHTS/BOA BISON/BOA VS491 2013_06_27 Rev_0.pdf. [Accessed: 07-Apr-2016].

[12] NOV - National Oilwell Varco, 'Anchor handling and towing winch', 2016. [Online]. Available: https://www.nov.com/Segments/Rig_Systems/Offshore/Lifting_and_Handling/Product_Catalogue/Anch or_Handling_Systems/Anchor_Handling_and_Towing_Winch/Anchor_Handling_and_Towing_Winch.a spx. [Accessed: 01-Feb-2016].

[13] L. Couce, Carrral, J. de Lara Rey, C. Alvarez-Feal, and J. Carral Couce, 'Winch control gear for CTD sampling with a system to compensate vertical motion heave when manoeuvring in rough seas', Ocean Eng., vol. 135, no. 2017, pp. 246-257, 2017.

[14] J. A. Carral Couce, L. M. Carral Couce, J. A. Fraguela Formoso, and J. L. Fernández Soto, 'El chigre de remolque en las maniobras de altura y de escolta: propuesta de armonización en sus parámetros de diseño', DYNA - Ind. y Energía, vol. 88, pp. 395-399, 2013.

[15] H. Langerak, 'Escort Tug - Tow Winch load Control', in Proceedings of The Tugnolog 09, 2009.

[16] L. Carral Couce, J. C. Carral Couce, and J. Fraguela Formoso, 'Operation and handling of escort tugboats by means of automatic towing winch systems', J. Navig., vol. 61, pp. 143-163, 2015.

[17] A. Nürnberg, 'Advanced VFD technology for deep water anchoring', Sh. Offshore, no. 6, pp. 42-48, 2010.

[18] J. Carral Couce, L. Carral Couce, J. Fraguela Formoso, and R. Villa Caro, 'Standardising the design and production of mooring winches through more cohesive regulations: a necessary step', Int. J. Marit. Eng. (RINA Trans. Part A), vol. 157, no. part A4. October-December 2015, 2015.

[19] V. De Angelis, 'Comparison study of electric, electro-hydraulic, and hydraulic drive science winches', 2009. .

[20] Z. Górski and M. Giernalczyk, 'Statistic determination of main propulsion power and total power of onboard electric power station on anchor handling tug supply vessels AHTS servicing oil rigs', J. Polish CIMEEAC, vol. 7, no. 1, 2013.

[21] H. Kverneland, 'Permanent magnet motors lead way to better power efficiency, safety on cranes, winches. Drilling contractor July- Aaugust 2008', 2008.

[22] S. Bjørhovde and R. Aasen, 'Parametric estimation of anchor handling / towing winches", in 71st Annual Conference of Society of Allied Weight Engineers, Inc., Bad Gögging and Manching, 2012.

[23] R. Faure Benito, 'Máquinas y Accionamientos Eléctricos’. Madrid, 2000.

[24] J. Ikäheimo, 'DriveIT Permanent Magnet Motors', 2002. .

[25] J. Troya Calatayud, C. Alvarez Feal, C. Fernández Garrido, and L. Carral Couce, 'Analysing the possibilities of using fuel cells in ships', Int. J. hydrogean energy, vol. 41, no. 29, pp. 2853-2866, 2016.

[26] M. Rabiul-Islam, Y. Guo, and J. Zhu, 'A review of offshore wind turbine nacelle: Technical challenges, and research and developmental trends', Renew. Sustain. Energy Rev., vol. 33, pp. 161-176, 2014. https://doi.org/10.1016/j.rser.2014.01.085.

[27] R. Munz, 'Popularity of permanent magnet motors is on the rise', 2014. [Online]. Available: http://www.pbsionthenet.net/article/72729/Popularity-of-permanent-magnet-motors-is-on-the-rise.aspx. [Accessed: 01-Feb-2016].

[28] D. Rojas, A. Sarasquete, and D. Rial, 'Consideraciones sobre la aplicación de motores eléctricos con tecnología de imanes permanentes para el accionamiento directo de maquinaria rotativa en buques', in 48 Sesiones Técnicas de Ingeniería Naval - Asociación de Ingenieros Navales de España - AINE, 2009.

[29] Vacon, 'Advanced winch technology for extracting oil deep under the sea', 2016. [Online]. Available: http://www.vacon.com/es-ES/Vacon/media/References/Advanced-winch-technology-for-extracting-oildeep-under-the-sea/. [Accessed: 20-Feb-2016].

[30] Salt Ship Design / Scana / Inpower, 'Permanent magnet technology from Inpower to Scana Propulsion', 2016. [Online]. Available: http://www.inpower.no/news/permanent-magnet-technology-from-inpowerto-scana-propulsion. [Accessed: 20-Feb-2016]. 
Miguel Lamas Pardo, Luis Carral,

Laura Castro-Santos, Juan Carlos Carral Couce
A review of the drive options of Offshore Anchor Handling Winches

Submitted: $\quad$ 10.06.2016. Miguel Lamas Pardo

Luis Carral Couce

Accepted: $\quad$ 15.05.2017. Laura Castro-Santos, laura.castro.santos@udc.es

Departamento de Enxeñaría Naval e Oceánica, Escola Politécnica Superior, Universidade da Coruña, Campus de Ferrol, 15471 Ferrol (A Coruña), Spain.

Juan Carlos Carral Couce

Carral Design Solutions (Spain). 